\title{
B-cell lymphoblastic leukaemia in a guinea-pig - a case report
}

\author{
Martin Levkut ${ }^{1}$, Peter Major ${ }^{2}$, Lucia Kottferová $^{2}$, Mikuláš Levkut ${ }^{1,3}$ \\ ${ }^{1}$ University of Veterinary Medicine and Pharmacy, Department of Morphological Disciplines, Košice, Slovakia \\ ${ }^{2}$ University of Veterinary Medicine and Pharmacy, Clinic of Birds, Exotic and Free-living Animals, Košice, Slovakia \\ ${ }^{3}$ Slovak Academy of Sciences, Institute of Neuroimmunology, Bratislava, Slovakia
}

Received December 24, 2020

Accepted May 26, 2021

\begin{abstract}
In this case report, lymphoblastic leukaemia is described in a five-year-old female guinea pig. Clinical examination revealed lymphadenopathy, mainly with increased size of the popliteal lymph nodes. Lymphoblast cells were determined haematologically. Postmortem findings were hepatomegaly and splenomegaly. Histopathological examination of liver, spleen and lymph nodes revealed tumour cells of lymphoblastic type. These cells showed considerable cellular pleomorphism. The protein markers CD3 and CD20 and paired box 5 (PAX5) transcription factor were traced immunohistochemically. Immunophenotypization using PAX5 showed nuclear positivity of this marker, but CD3 and CD20 (not interspecies cross-reactivity for guinea pig) demonstrated no positive reaction in the tumour cells. CD3-positive cells were found only in guinea pig tissue sections used as control. PAX5 in guinea pigs appears as a beneficial and preferred marker for B-cell derived tumours.
\end{abstract}

Immunohistochemistry, PAX5, rodent

Spontaneous tumours are generally uncommon in guinea pigs. Tumours rarely occur in guinea pigs less than three years old (Jelínek 2003; Koebrich et al. 2011; Lukášová et al. 2017). Female guinea pigs may be more likely to develop lymphoid tumours. Rarely observed lymphoblastic leukaemia shows prevalence in T-cell lymphoma (Koebrich et al. 2011; Heuer et al. 2014). Jelínek (2003) examined neoplasia in 19 guinea pigs without histological diagnosis of lymphoma. Similarly, Minarikova et al. (2015) found no lymphoma/leukaemia in a retrospective study involving 1,000 pet guinea-pigs.

This case report describes the clinical examination, histological, and immunohistochemical evaluation of lymphoblastic leukaemia in a female guinea-pig.

\section{Case presentation}

A five-year-old female guinea pig with a body weight of 860 grams was treated for gradually increasing weakness, lethargy, and decreased defecation. Enrofloxacin was administered therapeutically for three days, however, without improving the animal's health condition. The guinea pig was cachectic, afebrile, and without interest in her surroundings. Her hair was dull and the rectum was smeared with faeces. Stomatological examination and salivation showed maloclusion of the molars. Blood smear was stained with Hemacolor (Merck, Darmstadt, Germany) and examination revealed lymphoid tumour cells with intranuclear granulation of chromatin (Plate XVI, Fig. 1). Cell nuclei demonstrated morphological abnormalities (macrokaryosis, hyperchromatic nuclear membrane with distinct bordered pale cytoplasm). The owner declined treatment for the guinea pig and opted for euthanasia. The animal was heavily sedated using medetomidine (Cepetor, CP Pharma Handelsgesellschaft mbH, Burgdorf, Germany) $(0.2 \mathrm{mg} / \mathrm{kg}, \mathrm{sc})$ and ketamine (Ketamidor, Richter Pharma, Wels, Austria) (40 mg/kg, s.c.), followed by intra-cardiac administration

Address for correspondence:

Peter Major

Clinic of Birds, Exotic and Free-living Animals

University of Veterinary Medicine and Pharmacy

Komenského 73, Košice, Slovakia

Phone: +421908 495654

E-mail: major.dr@gmail.com

http://actavet.vfu.cz/ 
of $0.3 \mathrm{ml} / \mathrm{kg}$ of T-61 euthanasia solution (Intervet International B.V., Boxmeer, Netherlands). Postmortem findings included hepatomegaly, splenomegaly, and lymphadenopathy, mainly in the popliteal lymph nodes. Lymph nodes were asymmetrically enlarged, and the structure on cut surfaces was obscured. The liver was enlarged and pale brown and had a prominent lobular pattern with alternating areas of light tan and white. Samples (spleen, liver, and lymph nodes) taken for histological and immunohistochemical examination were fixed in $10 \%$ neutral buffered formalin and processed using the standard paraffin technique. For histological evaluation haematoxylin-eosin and Giemsa were used. Immunotypization of lymphocytes was done with CD20cy-mouse MoAb (dilution 1:200), clone L26 (Dako, Glostrup, Denmark); CD3-mouse MoAb (dilution1:50), clone F7.2.3 (Dako); PAX5-rabbit MoAb (ready-to-use), clone SP34 (Ventana Medical Systems, Tucson, Arizona). Reactions were visualized with the UltraView Universal DAB Detection Kit (Ventana Medical Systems). Control tissue was taken from the spleen of an intact guinea pig and human tissue from the cervical tonsils. Histological slides were evaluated by a Nikon Labophot 2 microscope (Nikon, Tokyo, Japan) and analysed with NIS element Advanced research 3.0 (Nikon). Histologically, tumour cells of lymphoblastic type were seen. These tumour cells revealed considerable cellular pleomorphism. Perivascular infiltration of lymphoid cells in aggregates were found in the spleen. Germinal centres of white pulp were increased in size and focally fused together, obscured with tumour cells (Plate XVI, Fig. 2). Tumorous expansion of germinal centres caused pressure on the structure of red pulp with higher quantity of siderophages. The liver showed extravascular and intravascular infiltration of blastic cells (Plate XVII, Fig. 3) with an altered nucleus-cytoplasm ratio. Small, round, and clear vacuoles were found in the cytoplasm of hepatocytes. However, special stains were not used for identification of lipids. The structure was evaluated as vacuolar degeneration. Lymph node structure was similarly obscured with tumour cells and rare observed mitoses (Plate XVII, Fig. 4). Immunophenotypization of tumour cells with PAX5 revealed nuclear positive reaction in the tumour cells (Plate XVIII, Fig. 5). The CD3 (T-cell) marker was negative in the tumour cells. Similarly, CD20 showed a negative reaction in those cells. However, CD3 applied to control spleen tissue from the intact guinea pig demonstrated a very clear reaction of cells in the T-cell zone (Plate XVIII, Fig. 6).

\section{Discussion}

Lymphatic leukaemia, rarely observed in guinea pigs, has previously been confirmed by means of haematological analysis in both irradiated and non-irradiated guinea pigs. One of the first who diagnosed a tumorous mass on the ventral part of the neck and in the right axilla of a guinea pig was Dickson (1915). It was histologically documented as a lymphoid type of tumour.

Several cases of leukaemia occurring in guinea pigs have been detected in females during pregnancy. However, necropsy did not confirm leukaemia in the foetus (Nadel et al. 1974). Only twelve cases of leukaemia and lymphoma in approximately 5,000 animals were described in the literature in 1991 (Steinberg 2000).

Several authors mention the application of CD79 and CD3 protein markers in differential diagnosis of B/T tumorous cells (Vezzali et al. 2010; Valli et al. 2011). In our case, protein markers CD3, CD20, and the transcription factor PAX5 were used for the determination of leukaemia in our female guinea pig.

CD20 is a general B-cell marker expressed during B-cell differentiation from the pro-B cell phase until the plasma cell stage (Boross and Leusen 2012). CD3 is a protein complex and T-cell co-receptor which is plugged in upon activation of T-cells, both cytotoxic $\left(\mathrm{T}_{\mathrm{c}}\right)$ and helper $\left(\mathrm{T}_{\mathrm{h}}\right)$ cells. The PAX5 gene is a member of the paired box (PAX) family of transcription factors expressed throughout B-cell maturation, and is detected in most 
B-cell neoplasms, including those lacking expression of mature B-cell markers (Desouki et al. 2010). PAX 5 is a B-cell marker and precursor which is more specific than CD79a. In human population, expression of PAX 5 is limited to malignant forms of B-cells only, where expression of CD20 and CD79 is absent (Jensen et al. 2007). In our case, PAX5-positivity of tumorous cells indicated a B-cell line tumorous population. However, using CD20 in our case demonstrated no interspecies cross-reactivity for guinea pig. CD3 cell positivity identified in control guinea pig spleen tissue using CD3-mouse MoAb is a useful immunohistochemical marker for T cells in tissue sections. The antigen remains present in almost all T-cell lymphomas and leukaemias. However, our control tissue section was negative for this marker, which supports our histological evaluation concerning B-cell lymphoblastic leukaemia.

In conclusion, acute lymphoblastic leukaemia is included in the progressive tumour diseases with a fatal outcome. PAX5, a B-cell transcription factor, was used for confirming the diagnosis in our case, and this marker is detected by immunohistochemistry in routine human biopsies. This protein demonstrated a cross-reaction in our guinea pig tumour cells. Diagnosis was confirmed by the presence of intracytoplasmic granules in the tumorous cells. Their detection plays a key role in diagnosis of these tumours. Positivity of cells to CD3 marker in the control tissue can be used as an immunohistochemical marker for $\mathrm{T}$ cells in guinea pig tissue sections.

\section{Acknowledgements}

This work was supported by the Grant Agency for Science of the Slovak Republic VEGA 1/0355/19, 1/0107/21 and the Slovak Research and Developmental Agency APVV-15-0165. We are thankful to T. Torday, Medicyt, s.r.o. for technical assistance in immunohistochemistry of samples.

\section{References}

Boross P, Leusen HW 2012: Mechanisms of action of CD20 antibodies. Am J Cancer Res 2: 676-690

Desouki MM, Ginell R, Cherry D, Lazarchick J 2010: PAX-5: Avaluable immunohistochemical marker in the differential diagnosis of lymphoid neoplasms. Clin Med Res 8: 84-88

Dickson EC 1915: Sarcoma occurring in a guinea-pig. Proc. Soc. Expert. Biology \& Medicine 13: 26-17

Heuer L, Stötter M, Eydner M, Puff CH, Kleinschmidt S 2014: Metastasizing epitheliotropic T-cell lymphoma (Mycosis fungoides) in two guinea pigs (Cavia porcellus). Berl Munch Tierarztl 127: 333-336

Jelínek F 2003: Spontaneous tumours in guinea pigs. Acta Vet Brno 72: 221-228

Jensen KC, Higghs JP, Montgomery K, Kaygusuz G, Van De Rijn M, Natkunam Y 2007: The utility of PAX immunohistochemistry in the diagnosis of undifferentiated malignant neoplasms. Modern Pathol 20: 871-877

Koebrich S, Grest P, Favrot C, Wilhelm S 2001: Epitheliotropic T-cell lymphoma in a guinea-pig. Veterinary Dermatol 22: 2015-2019

Lukašová R, Bártová E, Škorič M 2017: Leiomyosarcoma of the ovary in a young female guinea pig - a case report. Acta Vet Brno 86: 269-272

Minarikova A, Hauptman K, Jeklova E, Knotek Z, Jekl V 2015: Diseases in pet guinea pigs: a retrospective study in 1000 animals. Vet Rec 177: 200

Nadel E, Liu P, Burnstein S 1974: Experimental perinatal leukemia in guinea pigs. Beitr Pathol 151: 268-280

Steinberg H 2000: Disseminated T- cell lymphoma in a guinea pig with bilateral ocular involvement. J Vet Diagn Invest 12: 459-462

Valli VE, San Myint M, Barthel A, Bienzle D, Caswell J, Colbatzky F, Durham A, Ehrhart EJ, Johnson Y, Jones C, Kiupel M, Labelle P, Lester S, Miller M, Moore P, Moroff S, Roccabianca P, Ramos-Vara J, Ross A, Scase T, Tvedten H, Vernau W 2011: Classification of canine malignant lymphomas according to the World Health Organisation criteria. Vet Pathol 48: 198-211

Vezzali E, Parodi AL, Marcato PS, Bettini G 2010. Histopathological classification of 171 cases of canine and feline non-Hodgkin's lymphoma according to the WHO. Vet Comp Oncol 8: 38-49 
Plate XVI

Levkut M. et al.: B-cell ... pp. 221-223

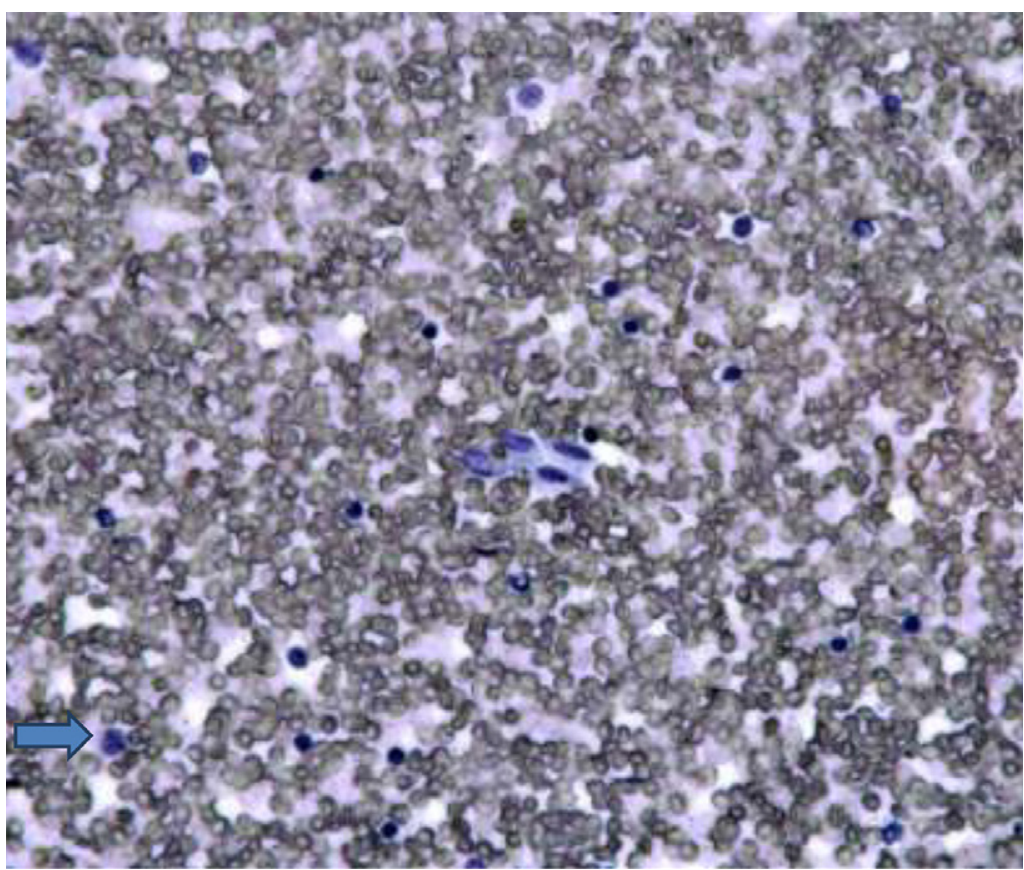

Fig. 1. Blood smear lymphoblastic cell (arrow), $\times 200$

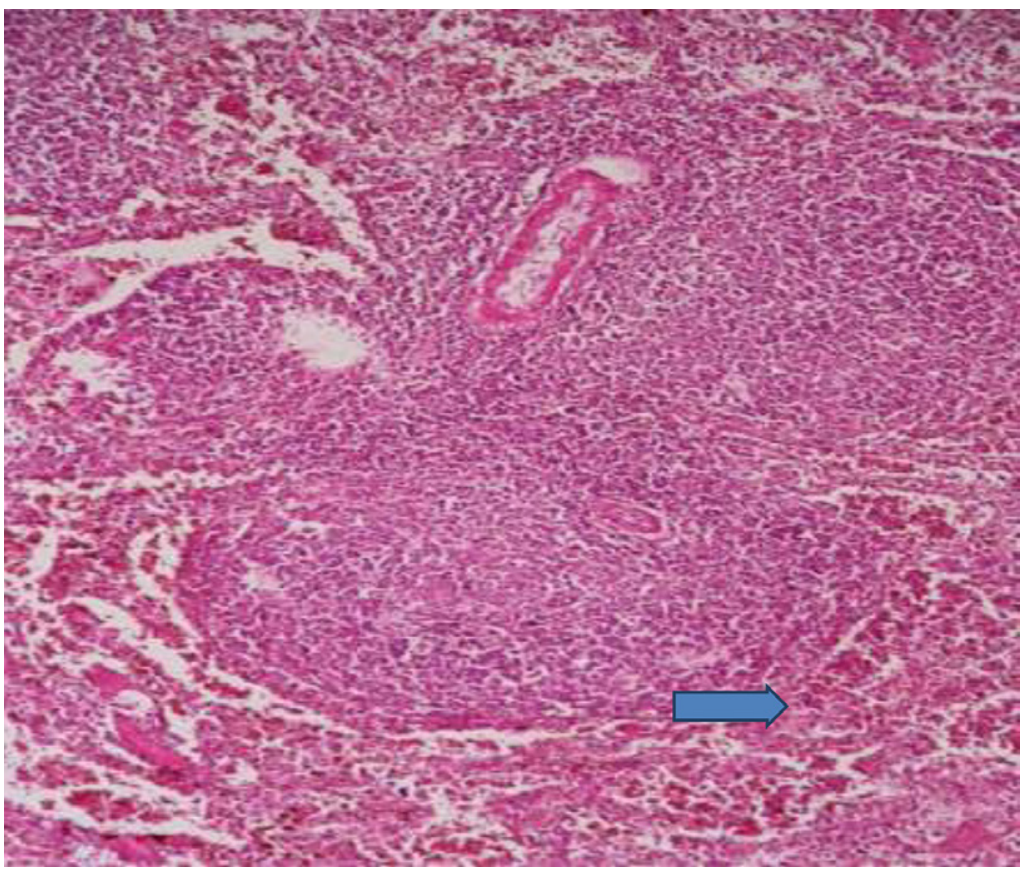

Fig. 2. Spleen-germinal centres increased in size and siderophages (arrow) in red pulp (haematoxylin-eosin, $\times 200$ ) 


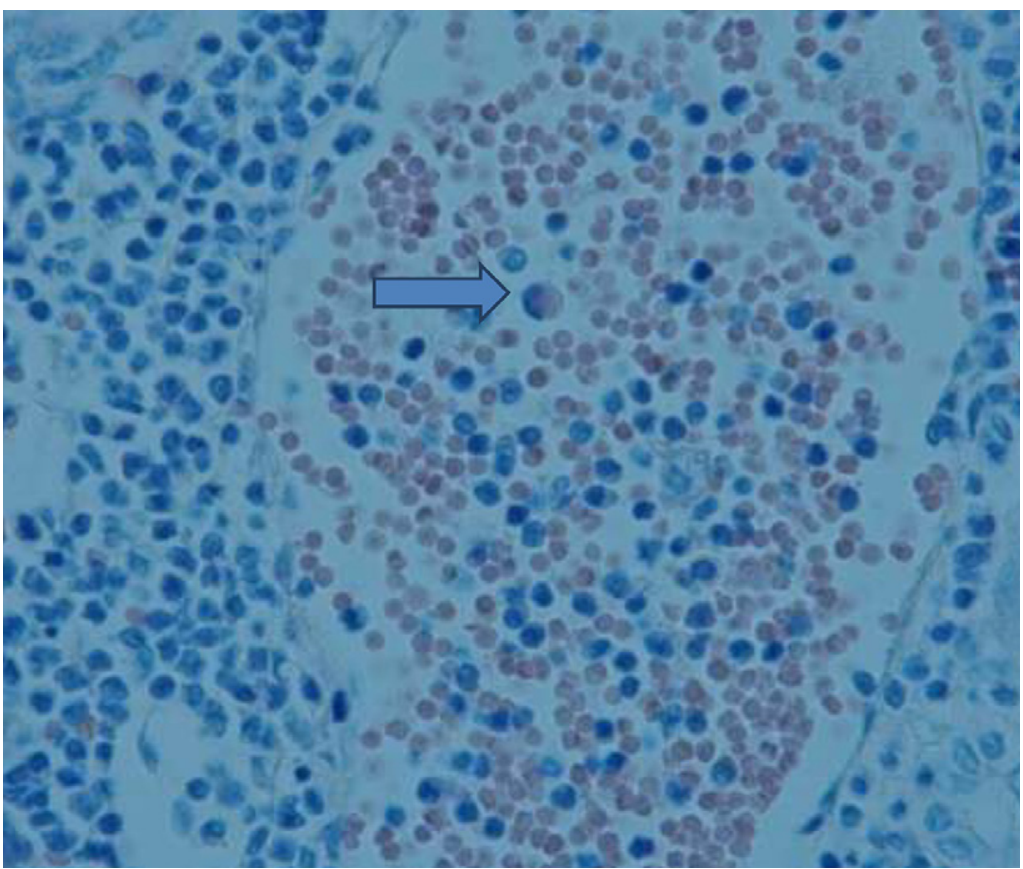

Fig. 3. Liver - extravascular and intravascular infiltration of blastic cells (arrow) (haematoxylin-eosin, $\times 400$ )

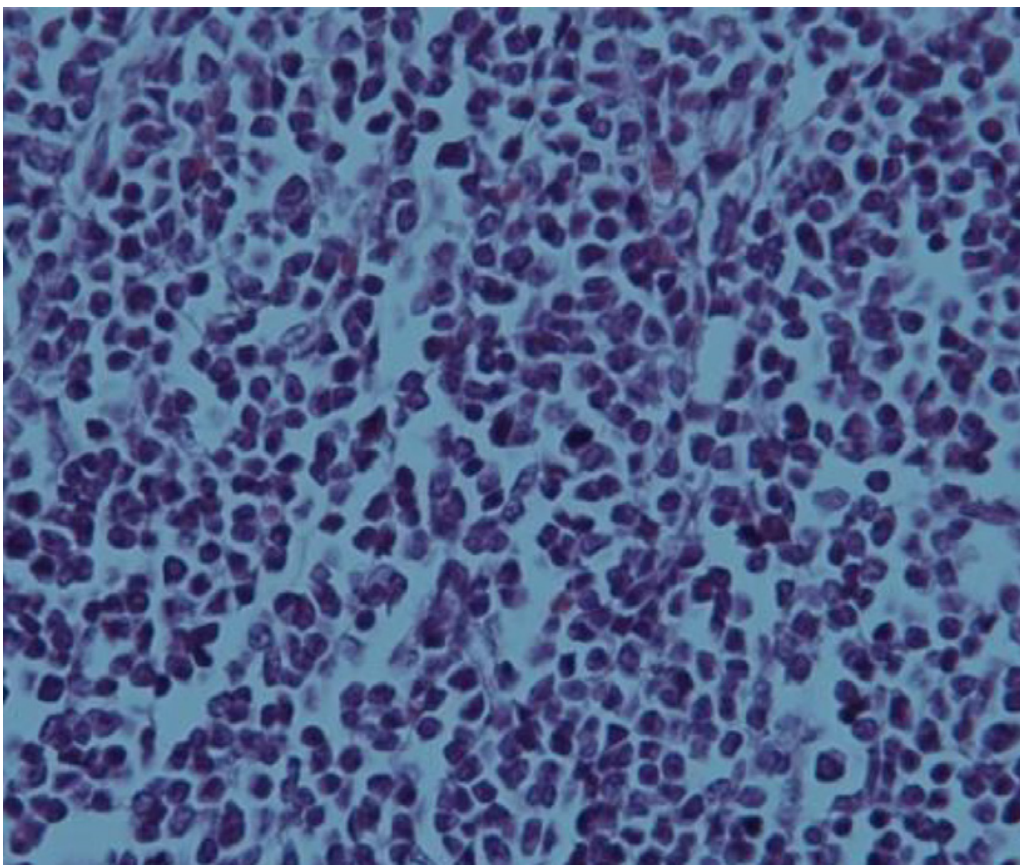

Fig. 4. Lymph node structure obscured with tumour cells (Giemsa, $\times 400)$. 


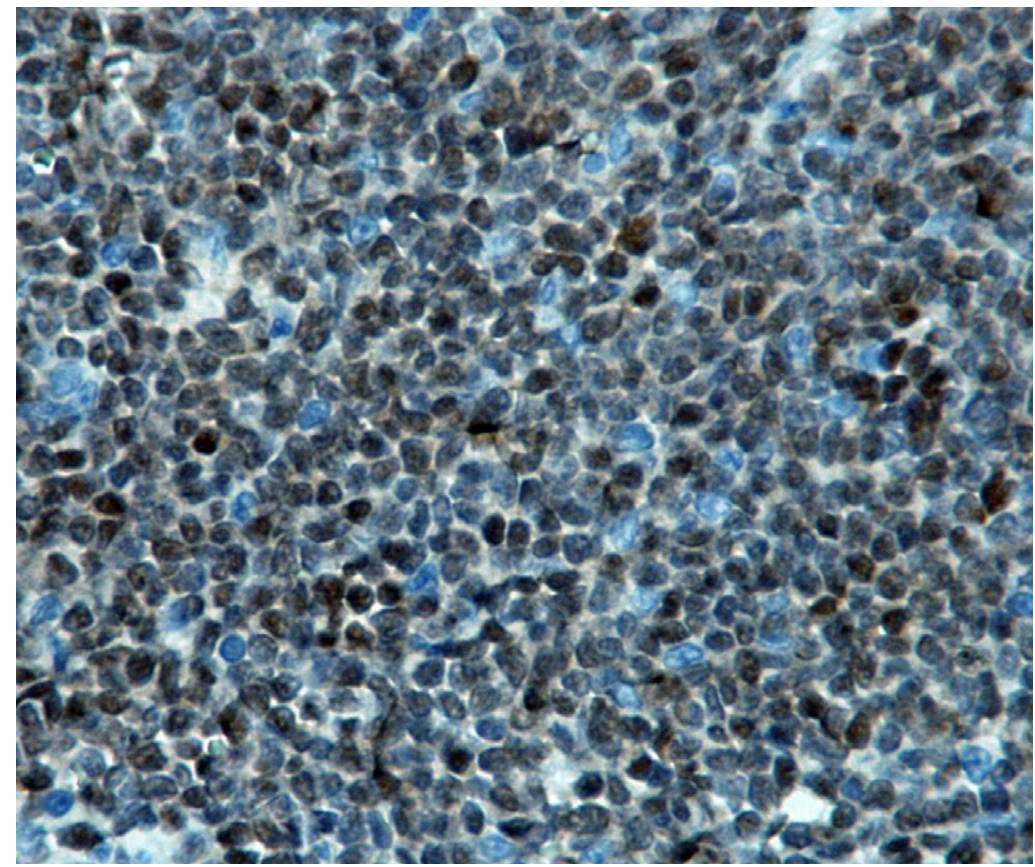

Fig. 5. PAX 5 marker in lymphoblastic cells $($ IHC: black-brown stained nuclei, $\times 400)$

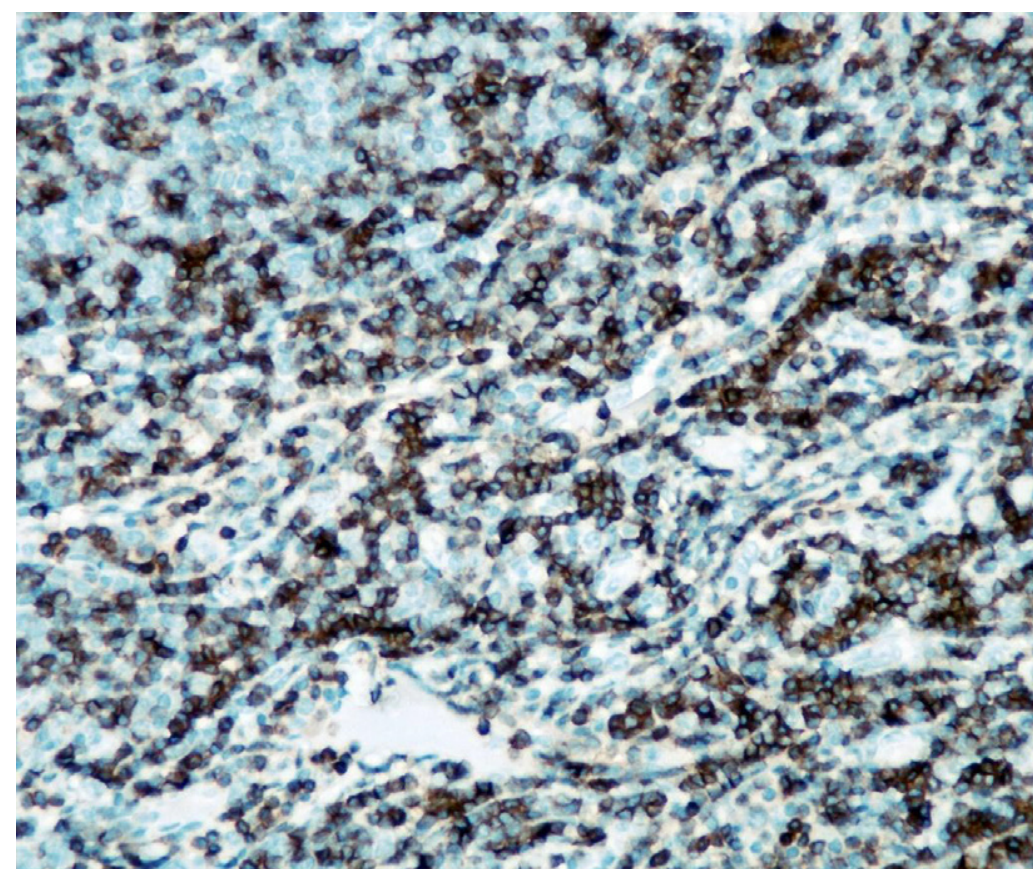

Fig. 6. Spleen- CD3 positive (control IHC, $\times 200)$ 